\title{
A review of endoscopic ultrasound guided endoscopic retrograde cholangiopancreatography techniques in patients with surgically altered anatomy
}

\author{
Rucha Mehta Shah, Paul Tarnasky, Prashant Kedia \\ Department of Gastroenterology, Methodist Dallas Medical Center, Dallas, TX, USA \\ Contributions: (I) Conception and design: All authors; (II) Administrative support: P Tarnasky, P Kedia; (III) Provision of study materials or patients: P \\ Kedia; (IV) Collection and assembly of data: All authors; (V) Data analysis and interpretation: None; (VI) Manuscript writing: All authors; (VII) Final \\ approval of manuscript: All authors. \\ Correspondence to: Prashant Kedia. Department of Gastroenterology, Methodist Dallas Medical Center, Dallas, TX, USA. Email: prashantkedia@mhd.com.
}

\begin{abstract}
Endoscopic retrograde cholangiopancreatography (ERCP) is the primary therapeutic intervention for pancreaticobiliary duct diseases. Surgically altered anatomy (SAA) makes performing successful ERCP challenging. In this review article the concept of endoscopic ultrasound guided pancreaticobiliary drainage (EUS-PBD) in cases of SAA where conventional ERCP fails or is not possible will be reviewed. EUS-PBD serves as an emerging and promising alternative for pancreaticobiliary therapy in the hands of skilled endoscopists compared to conventional therapies such as device-assisted ERCP, laparoscopic-assisted ERCP, or percutaneous drainage. The purpose of this review is to discuss the rationale, technique and current published outcomes on EUS-PBD for SAA.
\end{abstract}

Keywords: Endoscopic ultrasound guided endoscopic retrograde cholangiopancreatography (EUS-ERCP); endoscopic ultrasound guided pancreaticobiliary drainage (EUS-PBD); surgically altered anatomy (SAA)

Received: 17 September 2018; Accepted: 22 October 2018; Published: 09 November 2018.

doi: $10.21037 /$ tgh.2018.10.10

View this article at: http://dx.doi.org/10.21037/tgh.2018.10.10

\section{Introduction}

Endoscopic retrograde cholangiopancreatography (ERCP) is established as the gold standard for the management of disease of the bile and pancreas ducts with expected cannulation rates of $95-97 \%$ in the hands of high volume endoscopists for patients with native anatomy (1). With the increased prevalence of bariatric surgery as well as advanced pancreaticobiliary surgical approaches for tumor removal and liver transplants, it is becoming more common for endoscopists to encounter patients with surgically altered anatomy (SAA). Pancreaticobiliary access in SAA patients has been conventionally attempted by enteroscopyassisted ERCP (EA-ERCP) however with limited success rates of $69.4 \%$ (2). Other alternatives for SAA patients include percutaneous or surgical intervention, which may be successful, but are limited by longer recover times, patient discomfort and significant rates of adverse events related to indwelling catheters and surgical recovery. Thus, the need for more minimally invasive means for pancreaticobiliary access in SAA patients is apparent has led to the development of endoscopic ultrasound (EUS) guided access techniques. EUS-guided pancreaticobiliary drainage (EUS-PBD) is based on the concept of accessing the pancreatic or biliary system using a EUS needle, through which wire access and various routes of drainage can be achieved. Because pancreaticobiliary access is performed transmurally usually from the stomach or proximal duodenum, this can be very useful in SAA. EUS-PBD can be indicated in cases of choledocholithiasis, post-operative leakage, strictures, and cholangitis (3). EUS guided biliary drainage (EUS-BD) was first described in 2001 by Giovannini et al. for treatment of obstructive jaundice caused by pancreatic head mass and resultant dilated common bile duct (4). EUS-BD serves as an alternative for 
enteroscopy-assisted ERCP, laparoscopic-assisted ERCP, and percutaneous transhepatic biliary drainage. Several advantages exist when performing EUS-BD, including the ability to perform it in the same session after failed ERCP, possibility to perform intra and extrahepatic $(\mathrm{EH})$ drainage, using a minimally invasive approach, overall shorter hospital stays and lower adverse events than percutaneous drainage (5-8).

\section{Techniques}

Currently EUS-BD involves three different techniques for biliary drainage: anterograde, transluminal, and rendezvous method. Anterograde EUS-BD involves achieving wire access in an antegrade fashion across ampulla or bilioenteric or pancreaticoenteric anastomosis to achieve drainage. Transluminal drainage implies creating a new pancreaticoenteric or bilioenteric fistula. The rendezvous method includes placement of a guidewire across the ampulla/anastomosis itself, which can then be grasped or utilized by a duodenoscope to perform conventional ERCP. For patients with SAA, generally the rendezvous method is of limited utility given the decreased ability to endoscopically access the ampulla.

\section{Rendezvous technique}

Similar to percutaneous access of the papilla via guidewire, this technique employs EUS guidance for ampullary access and cannulation. Using endosonography and fluoroscopy, the bile duct or pancreas duct can be accessed by a transgastric or transduodenal approach with a $19 \mathrm{G}$ fine needle aspirate (FNA) needle. Through the needle, a guidewire is advanced across the ampulla or anastomosis and looped into the small intestine. After this placement is secured, the echoendoscope is removed and conventional ERCP can be reattempted with the guidewire in place as an access point to the pancreaticobiliary system (3). While the rendezvous technique can be used to access both intrahepatic (IH) and EH bile ducts, the success rate in case reports has varied from $35-100 \%$ (9-16). The range of complications has been reported to be from 10-25\% (9-18). Post-procedure bile leak and peritonitis are the most feared, as well as pancreatitis, pneumoperitoneum, abdominal pain, and sepsis $(17,18)$.

\section{Antegrade drainage}

Steps for performing this are identical to the rendezvous, by creating an enterobiliary or enteropancreatic fistula initially to access the ductal system. Placement of guidewire is done through a 19G FNA needle, followed by with dilation of the bilioenteric or pancreaticoenteric tract to allow for device passage. Once this is in place, various therapeutic interventions such as stent placement, balloon dilation, or sphincteroplasty can be performed through the EUS scope in an antegrade fashion. The goal of antegrade drainage is to place a stent across the ampulla or anastomosis itself just as one would achieve in conventional ERCP. Antegrade EUS-BD in SAA has been shown to have a clinical and technical success rate of $95 \%$ with a mild adverse event rate of $20 \%$ (8). One limitation of this approach is that a biliary sphincterotomy is not performed prior to intervention, and thus may theoretically increase the rate of pancreatitis if large metal stents are placed. Although a procedural risk is causing a bile leak, no cases of biliary peritonitis from the temporary fistula creation have been reported (19).

\section{Transluminal approach}

In the transluminal approach, the concept is to create a pancreatico or bilioenteric fistula proximal to the level of obstruction to bypass the blockage and achieve a new route of drainage. EUS-guided biliary or pancreatic duct access can be achieved with a 19G needle through which a guidewire can be placed in the obstructed duct. After securing the guidewire in the duct of choice placement of a transmural stent can be performed. When using the guidewire method usually the fistula needs to be dilated prior to stent placement. However, with new electrocauteryenhanced catheter deliver systems of lumen-apposing metal stents, it is possible to directly puncture the place a stent from the duodenal bulb into the $\mathrm{EH}$ bile duct in a single step (20). Preferred approaches include hepaticogastric (HG) or choledochoduodenal (CD). To avoid bile leaks and peritonitis, uncovered metal stents should not be used with the transmural approach (3). During transmural EUSPD generally a small caliber plastic pancreatic duct stent (5-7 Fr) is placed from the stomach directly into the main pancreas duct.

\section{Tools and techniques}

EUS-BD can be performed safely for indications of IH or $\mathrm{EH}$ diseases. For EH, a linear echoendoscope is advanced to the duodenum or distal antrum, from where the dilated EH biliary tree can be more easily accessed. The goal is to 
Table 1 Tools and techniques

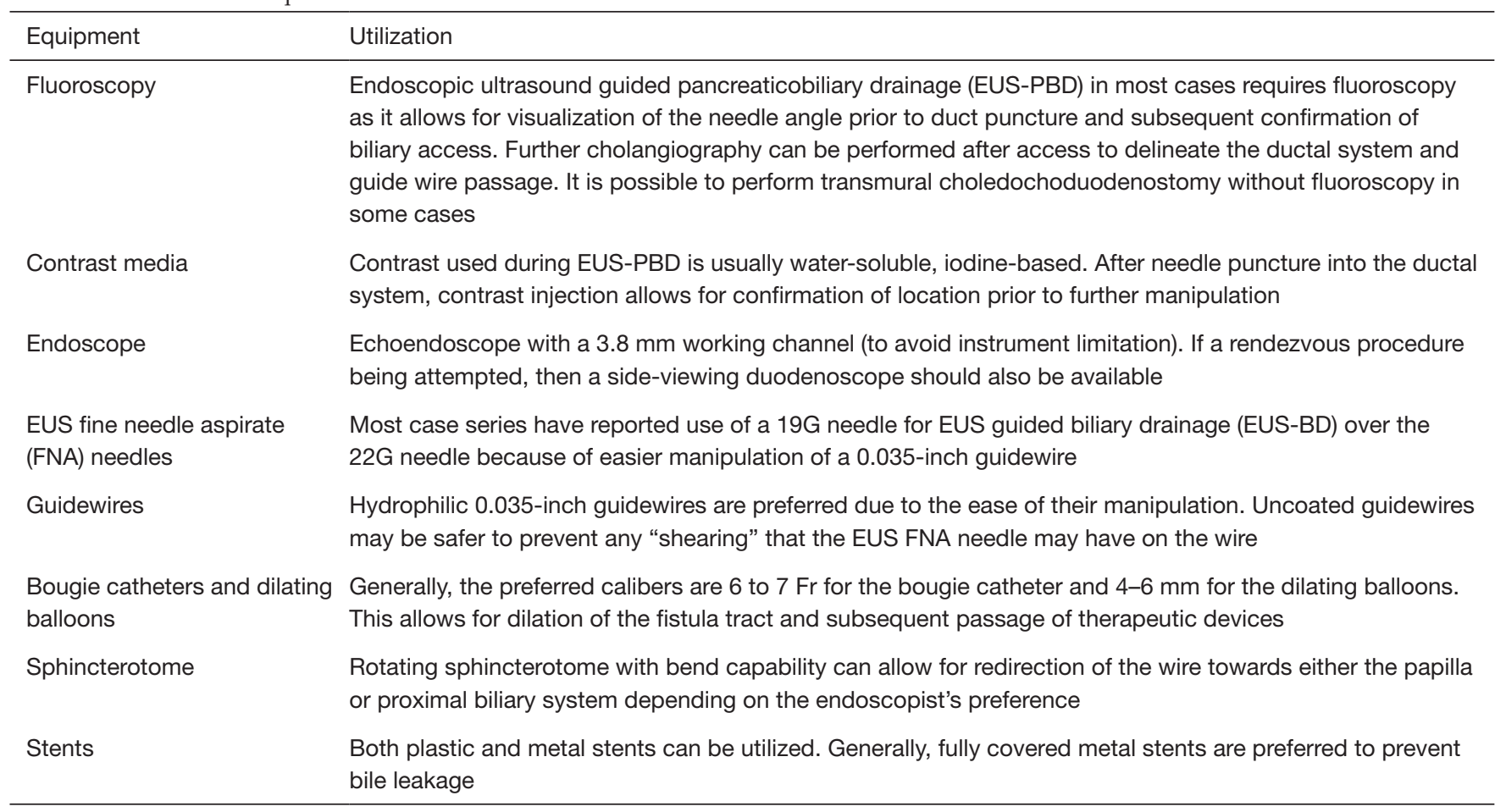

obtain the shortest approach to a large target EH bile duct that gives the endoscopist the best control over therapeutic maneuvers. For IH disease, a linear echoendoscope is advanced to the gastric cardia or lesser curvature, for a transgastric approach to target the dilated left hepatic biliary system. Given that that ampulla is difficult to access in many SAA cases, generally rendezvous techniques are of limited utility in this population. If the ampulla or anastomosis is not easily accessible, generally the antegrade approach is preferred, and if this fails a transmural approach can be utilized.

To maximize chances of success and minimize complications it is important to have a plan of approach along with all the necessary equipment easily available prior to beginning a EUS-PBD procedure. The following tools are important for the procedure (Table 1).

\section{Altered anatomy}

Surgically altered anatomies where the duodenum and major papilla are not accessible endoscopically and require non-standard endoscopic techniques include Billroth II, Roux-en-Y gastric bypass (RYGB), classic and pylorus preserving pancreaticoduodenectomy (Whipple), Roux-
en-Y hepaticojejunostomy (HJ). Success rates of ERCP in patients with SAA has been quoted to be as low at 51-55\%, due to inability to reach the papilla secondary to acute angulations or distance to the papilla, with complications seen in up to $20 \%$ of cases (21-26).

\section{Billroth II}

Billroth II is usually indicated for treatment of gastric cancer or severe peptic ulcer disease. It is performed as a subtotal distal gastrectomy, with the proximal stomach attached to the proximal jejunum in an end-toside anastomosis. Access to the papilla occurs through the afferent jejunal limb. Endoscopic challenges with this anatomy include angles and adhesions that can develop post operatively, as well as orientation of the ampulla being reversed from native anatomy. This makes cannulation much more difficult and alternate methods such as opposite direction cannulation or use of a straight catheter may need to be employed (3). There is also an increased rate of bowel perforation at the gastrojejunal anastomosis with duodenoscope advancement. A large series of 713 patients undergoing ERCP with Billroth II anatomy showed an overall cannulation rate of $81.3 \%$, 
$4.3 \%$ adverse event rate with $1.8 \%$ incidence of bowel perforation (27). Generally, ERCP in patients with Billroth II can be achieved with a standard duodenoscope with the patient in the prone position. EUS can be safely performed in patients with Billroth II altered anatomy. The linear echoendoscope is better for visualizing the bile duct and pancreatic head, as well as for the pancreatic neck (3). In a group of 25 patients with altered anatomy, forward viewing echoendoscope allowed visualization of the head of the pancreas and the common bile duct in all of the patients (28). The rendezvous approach may be reasonable in Billroth II anatomy if the duodenoscope can be advanced to the ampulla, otherwise an antegrade approach would be the best alternative.

\section{Roux-en-Y gastric bypass (RYGB)}

RYGB serves as a very common bariatric operation for weight loss. The procedure includes creation of a gastric pouch from the proximal stomach (between 15 and $30 \mathrm{~mL}$ ), exclusion of the remnant stomach, and creation of a gastrojejunal anastomosis between the pouch and the distal jejunum to create the roux limb. The excluded stomach remains connected to the duodenum and jejunum, and is termed the biliopancreatic limb, through which biliary and pancreatic secretions flow. It is this afferent limb that must be accessed for conventional ERCP to be performed. Challenges in RYGB with accessing the ampulla include the distance to reach the ampulla, which can be upwards of a $100-150 \mathrm{~cm}$, tight angulation of the jejunojejunal anastomosis, and postoperative adhesions $(3,29)$. Conventional duodenoscopes usually cannot reach the ampulla, thus EA-ERCP has been used. EA-ERCP is limited due to challenging scope positions and an inability to use conventional ERCP tools without an elevator (3). Successful PB intervention with EA-ERCP in bariatric patients has been reported to be as low as $63 \%$ in multicenter studies (30).

To circumvent the need to EA-ERCP, EUS-directed transgastric ERCP (EDGE) was first described in 2014 to perform conventional therapeutic ERCP in patients with RYGB using EUS-guided access of the excluded stomach. The technique involves EUS-guided creation of gastrogastric or jejunogastric fistula, via placement of a fully covered, lumen-apposing metal stent (LAMS) to access the excluded stomach and perform conventional anterograde ERCP (19). A key technical aspect of the EDGE procedure is to use a LAMS with a large diameter $(\geq 15 \mathrm{~mm})$ to prevent leakage and allow for passage of a duodenoscope. Generally, for non-emergent indications, EDGE is performed in 2 stages to allow for maturation of the fistula and reduce the risk of stent migration during passage of the duodenoscope. If stent migration occurs and there is a not a mature fistula tract (which may require around 4 weeks to form), then a free perforation of the excluded stomach may occur and require emergent surgical intervention. The fistula can be left open with a LAMS in place until completion of all endoscopic therapy has been achieved. Once further interventions are not planned, the stent can be removed and gastric or jejunal defect can be closed endoscopically (with clips or suturing). Early outcomes of the EDGE procedure have been encouraging with successful therapeutic ERCP intervention in $96.5 \%$ of cases. EDGE was found to be non-inferior to LA-ERCP in terms of efficacy and safety, with shorter procedure time and hospital stay (31). EDGE has also been compared to EA-ERCP and been shown to have higher technical success $(100 \%$ vs. $60 \%)$, shorter procedure times (49.8 vs. $90.7 \mathrm{~min}$ ), shorter hospital length of stay (1 vs. 10.5 days) and comparable rates of adverse events (10\% vs. 6.7\%) (32). The concern of possible weight gain with temporary RYGB reversal has not been substantiated as current studies have reported weight loss after the EDGE procedure $(31,33)$.

\section{Whipple procedure (pancreaticoduodenectomy)}

The Whipple procedure is employed primarily for treating cancer at the head of the pancreas, common bile duct, ampulla of Vater or duodenum near the pancreas. It can be performed with pylorus preserving technique as well. Resultant altered anatomy includes total loss of ampulla with subsequent anatomic markers. Postsurgical anastomoses include a pancreaticojejunostomy, choledochojejunostomy, and gastrojejunostomy. Challenges associated with performing ERCP postWhipple include difficulty identifying and intubating the afferent limb to access the choledochojejunostomy or pancreaticojejunostomy due to angulations and adhesions. In general, ERCP in patients with Whipple anatomy can be achieved with a pediatric colonoscope with the patient in supine position. The overall success rates of colonoscope-performed ERCP and EA-ERCP in Whipple anatomy for biliary access ranges from $84-93 \%$ (34-36). Pancreatic duct access however is much more challenging with significantly lower success rates with anecdotal success rates of $8 \%$ (36). Conventionally patients with 
pancreas duct disease after Whipple resection require some form of surgical intervention for management including reoperation of the anastomosis, Peustow, or possible completion pancreatectomy. EUS-PD is a significant improvement over conventional ERCP attempts and may help avoid the need for surgery in these patients. Multiple international multicenter studies on EUS-PD in Whipple anatomy have shown technical success rates of $89-92 \%$, clinical success rates of $81-88 \%$, and overall adverse events of $20-35 \%$, which were mild to moderate in nature $(37,38)$.

\section{Roux-en-Y HF}

Roux-en-Y HJ or choledochojejunostomy (bilioenteric anastomosis) is performed for select cases of biliary stricture, bile duct injury, or bile duct tumor. Conventional access of the bilioenteric anastomosis with a duodenoscope or colonoscope is very challenging and often not possible due to the length of the roux limb. EA-ERCP access in $\mathrm{HJ}$ has reported clinical success rates of $82 \%$ (35). EUS guided hepaticoenterostomy (EUS-HE) can been used to locate and access left sided IH ducts from the stomach or jejunum to create a $\mathrm{HE}$, through which various forms of intervention can be achieved. Early case series have reported technical success rates of $92 \%$ and adverse event rates of $8.1 \%$ with EUS-guided antegrade biliary interventions $(5,39)$. EUS-HE has been described in one or two stage procedures. In a single stage procedure, the interventions mimic those described above of the EUS-BD antegrade therapy. In two stage proceduresa hepaticoenteric fistula is formed with an $8-10 \mathrm{~mm}$ fully covered metal stent through which an ultraslim endoscope or cholangioscope can be passed at the second procedure for biliary intervention (i.e., lithotripsy, biopsy, etc.). Early experiences with EUS-HE have been reported with reasonable success and adverse event rates $(40,41)$.

\section{EUS-PBD: current evidence}

In recent years, EUS-PBD for various indications has been increasingly performed at expert EUS centers with encouraging outcomes. A large meta-analysis of 1,192 EUS-BD patients revealed technical success rates, clinical success rates, and adverse event rates of $94.7 \%, 91.7 \%$, and $23.3 \%$ (42). There is no significant difference in the overall technical success and safety of transhepatic or transduodenal access $(42,43)$. In comparison to percutaneous biliary drainage EUS-BD has been shown in multiple studies to

(C) Translational Gastroenterology and Hepatology. All rights reserved. have higher clinical success rates, lower rates of adverse events and reintervention, along with lower hospital length of stay and costs $(5,44-46)$. When comparing EUS-BD to EA-ERCP in an international comparative study, the technical and success was higher for EUS-BD (98\% vs. $65 \%$ and $88 \%$ vs. $59 \%$ ), with shorter procedure times (55 vs. $95 \mathrm{~min}$ ); although length of hospital stay and adverse events were more common in the EUS-BD $(47,48)$. As a mode of primary biliary intervention for distal malignant biliary obstruction EUS-BD has also been compared to ERCP in retrospective and prospective trials showing similar clinical success of achieving biliary drainage (>90\%) but with possible benefits of lower rates of post-procedure pancreatitis and need for biliary reintervention due to increase stent patency (49-51). With the current available evidence, it suggests that EUS-PBD is a reasonable and possibly superior method of biliary drainage compared to percutaneous and EA-ERCP methods in centers of EUS expertise.

\section{Conclusions}

For bile and pancreatic ductal disease, ERCP serves as the gold standard for management and therapeutic interventions. High success rates are seen in native anatomy, but SAA proves to be more challenging. Existing alternatives to endoscopic therapy including percutaneous and surgical intervention have significant limitations. Thus EUS-PBD has emerged as a minimally invasive option that can be performed in single sessions after failed conventional ERCP in patients with SAA, with the ability to deploy stents, use balloon dilator systems, and provide treatment for pancreaticobiliary diseases. Currently it has only been seen as a second line therapeutic approach after failed conventional ERCP. Further evidence is needed to determine if it should be used in distinct cases of primary biliary intervention over conventional ERCP as this would be a monumental shift in clinical practice.

As endoscopic techniques and technologies continue to advance, in the hands of expert echoendoscopists, EUSPBD serves as a promising route for pancreatobiliary interventions in patients with SAA to have interventions traditionally only possible via device-assisted ERCP, laparoscopic-assisted ERCP, or percutaneous drainage.

\section{Acknowledgements}

None. 


\section{Footnote}

Conflicts of Interest: The authors have no conflicts of interest to declare.

\section{References}

1. Baron TH, Petersen BT, Mergener K, et al. Quality indicators for endoscopic retrograde cholangiopancreatography. Am J Gastroenterol 2006;101:892-7.

2. Inamdar S, Slattery E, Sejpal DV, et al. Systematic review and meta-analysis of single-balloon enteroscopy-assisted ERCP in patients with surgically altered GI anatomy. Gastrointest Endosc 2015;82:9-19.

3. Jirapinyo P, Lee LS. Endoscopic Ultrasound-Guided Pancreatobiliary Endoscopy in Surgically Altered Anatomy. Clin Endosc 2016;49:515-29.

4. Giovannini M, Moutardier V, Pesenti C, et al. Endoscopic ultrasound-guided bilioduodenal anastomosis: a new technique for biliary drainage. Endoscopy 2001;33:898-900.

5. Sharaiha RZ, Khan MA, Kamal F, et al. Efficacy and safety of EUS-guided biliary drainage in comparison with percutaneous biliary drainage when ERCP fails: a systematic review and meta-analysis. Gastrointest Endosc 2017;85:904-14.

6. Giovannini M. Multicenter randomized phase II study: Percutaneous biliary drainage vs. EUS guided biliary drainage: Results of interim analysis. Gastrointest Endosc 2015;81:AB171.

7. Khashab MA, Valeshabad AK, Afghani E, et al. A comparative evaluation of EUS-guided biliary drainage and percutaneous drainage in patients with distal malignant biliary obstruction and failed ERCP. Dig Dis Sci 2015;60:557-65.

8. Iwashita T, Yasuda I, Mukai T, et al. Endoscopic ultrasound-guided antegrade biliary stenting for unresectable malignant biliary obstruction in patients with surgically altered anatomy: Single-center prospective pilot study. Dig Endosc 2017;29:362-8.

9. Mallery S, Matlock J, Freeman ML. EUS-guided rendezvous drainage of obstructed biliary and pancreatic ducts: Report of 6 cases. Gastrointest Endosc 2004;59:100-7.

10. Kahaleh M, Yoshida C, Kane L, et al. Interventional EUS cholangiography: A report of five cases. Gastrointest Endosc 2004;60:138-42.
11. Kahaleh M, Wang P, Shami VM, et al. EUS-guided transhepatic cholangiography: report of 6 cases. Gastrointest Endosc 2005;61:307-13.

12. Brauer BC, Chen YK, Fukami N, et al. Single-operator EUS-guided cholangiopancreatography for difficult pancreaticobiliary access (with video). Gastrointest Endosc 2009;70:471-9.

13. Tarantino I, Barresi L, Repici A, et al. EUS-guided biliary drainage: a case series. Endoscopy 2008;40:336-9.

14. Maranki J, Hernandez AJ, Arslan B, et al. Interventional endoscopic ultrasound-guided cholangiography: long-term experience of an emerging alternative to percutaneous transhepatic cholangiography. Endoscopy 2009;41:532-8.

15. Shah JN, Marson F, Weilert F, et al. Singleoperator, single-session EUS-guided anterograde cholangiopancreatography in failed ERCP or inaccessible papilla. Gastrointest Endosc 2012;75:56-64.

16. Dhir V, Bhandari S, Bapat M, et al. Comparison of EUSguided rendezvous and precut papillotomy techniques for biliary access (with videos). Gastrointest Endosc 2012;75:354-9.

17. Dhir V, Bhandari S, Bapat M, et al. Comparison of transhepatic and extrahepatic routes for EUS-guided rendezvous procedure for distal CBD obstruction. United European Gastroenterol J 2013;1:103-8.

18. Iqbal S, Friedel DM, Grendell JH, et al. Outcomes of endoscopic-ultrasound-guided cholangiopancreatography: a literature review. Gastroenterol Res Pract 2013;2013:869214.

19. Kedia P, Sharaiha RZ, Kumta NA, et al. Internal EUSdirected transgastric ERCP (EDGE): game over. Gastroenterology 2014;147:566-8.

20. Kumar M, Shapira G, Wiles A, et al. Endoscopic Ultrasound-Guided Choledochoduodenostomy Using a Lumen-Apposing Metal Stent in Pancreatic Head Neoplasm-Associated Biliary Obstruction. ACG Case Rep J 2018;5:e41.

21. Nguyen NT, Masoomi H, Magno CP, et al. Trends in use of bariatric surgery, 2003-2008. J Am Coll Surg 2011;213:261-6.

22. Siegel RL, Miller KD, Jemal A. Cancer statistics, 2015. CA Cancer J Clin 2015;65:5-29.

23. Nosher JL, Bodner LJ, Girgis WS, et al. Percutaneous gastrostomy for treating dilatation of the bypassed stomach after bariatric surgery for morbid obesity. AJR Am J Roentgenol 2004;183:1431-5.

24. Stein EG, Cynamon J, Katzman MJ, et al. Percutaneous gastrostomy of the excluded gastric segment after 
Roux-en-Y gastric bypass surgery. J Vasc Interv Radiol 2007;18:914-9.

25. Al-Lehibi AH, Kumar N, Sayuk GS, et al. M1463: Success Rates for Endoscopic Retrograde Cholangiopancreatography (ERCP) in Patients With Altered Anatomy From Prior Surgical Intervention. Gastrointestinal Endoscopy 2010;71:AB228.

26. Moreels TG. Endoscopic retrograde cholangiopancreatography in patients with altered anatomy: How to deal with the challenges? World J Gastrointest Endosc 2014;6:345-51.

27. Bove V, Tringali A, Familiari P, et al. ERCP in patients with prior Billroth II gastrectomy: report of 30 years' experience. Endoscopy 2015;47:611-6.

28. Fusaroli P, Serrani M, Lisotti A, et al. Performance of the forward-view echoendoscope for pancreaticobiliary examination in patients with status post-upper gastrointestinal surgery. Endosc Ultrasound 2015;4:336-41.

29. Enestvedt BK, Kothari S, Pannala R, et al. Devices and techniques for ERCP in the surgically altered GI tract. Gastrointest Endosc 2016;83:1061-75.

30. Shah RJ, Smolkin M, Yen R, et al. A multicenter, U.S. experience of single-balloon, double-balloon, and rotational overtube-assisted enteroscopy ERCP in patients with surgically altered pancreaticobiliary anatomy (with video). Gastrointest Endosc 2013;77:593-600.

31. Kedia P, Tarnasky PR, Nieto J, et al. EUS-directed Transgastric ERCP (EDGE) Versus Laparoscopy-assisted ERCP (LA-ERCP) for Roux-en-Y Gastric Bypass (RYGB) Anatomy: A Multicenter Early Comparative Experience of Clinical Outcomes. J Clin Gastroenterol 2018. [Epub ahead of print].

32. Bukhari M, Kowalski T, Nieto J, et al. An international, multicenter, comparative trial of EUS-guided gastrogastrostomy-assisted ERCP versus enteroscopyassisted ERCP in patients with Roux-en-Y gastric bypass anatomy. Gastrointest Endosc 2018;88:486-94.

33. Tyberg A, Nieto J, Salgado S, et al. Endoscopic Ultrasound (EUS)-Directed Transgastric Endoscopic Retrograde Cholangiopancreatography or EUS: Mid-Term Analysis of an Emerging Procedure. Clin Endosc 2017;50:185-90.

34. Li K, Huang YH, Yao W, et al. Adult colonoscopy or single-balloon enteroscopy-assisted ERCP in long-limb surgical bypass patients. Clin Res Hepatol Gastroenterol 2014;38:513-9.

35. Itokawa F, Itoi T, Ishii K, et al. Single- and doubleballoon enteroscopy-assisted endoscopic retrograde cholangiopancreatography in patients with Roux-en-Y plus hepaticojejunostomy anastomosis and Whipple resection. Dig Endosc 2014;26 Suppl 2:136-43.

36. Chahal P, Baron TH, Topazian MD, et al. Endoscopic retrograde cholangiopancreatography in post-Whipple patients. Endoscopy 2006;38:1241-5.

37. Chen YI, Levy MJ, Moreels TG, et al. An international multicenter study comparing EUS-guided pancreatic duct drainage with enteroscopy-assisted endoscopic retrograde pancreatography after Whipple surgery. Gastrointest Endosc 2017;85:170-7.

38. Tyberg A, Sharaiha RZ, Kedia P, et al. EUS-guided pancreatic drainage for pancreatic strictures after failed ERCP: a multicenter international collaborative study. Gastrointest Endosc 2017;85:164-9.

39. Mukai S, Itoi T, Sofuni A, et al. EUS-guided antegrade intervention for benign biliary diseases in patients with surgically altered anatomy (with videos). Gastrointest Endosc 2018. [Epub ahead of print].

40. James TW, Fan YC, Baron TH. EUS-guided hepaticoenterostomy as a portal to allow definitive antegrade treatment of benign biliary diseases in patients with surgically altered anatomy. Gastrointest Endosc 2018;88:547-54.

41. Iwashita T, Nakai Y, Hara K, et al. Endoscopic ultrasoundguided antegrade treatment of bile duct stone in patients with surgically altered anatomy: a multicenter retrospective cohort study. J Hepatobiliary Pancreat Sci 2016;23:227-33.

42. Wang K, Zhu J, Xing L, et al. Assessment of efficacy and safety of EUS-guided biliary drainage: a systematic review. Gastrointest Endosc 2016;83:1218-27.

43. Uemura RS, Khan MA, Otoch JP, et al. EUS-guided Choledochoduodenostomy Versus Hepaticogastrostomy: A Systematic Review and Meta-analysis. J Clin Gastroenterol 2018;52:123-30.

44. Téllez-Ávila FI, Herrera-Mora D, Duarte-Medrano G, et al. Biliary Drainage in Patients With Failed ERCP: Percutaneous Versus EUS-guided Drainage. Surg Laparosc Endosc Percutan Tech 2018;28:183-7.

45. Sportes A, Camus M, Greget $M$, et al. Endoscopic ultrasound-guided hepaticogastrostomy versus percutaneous transhepatic drainage for malignant biliary obstruction after failed endoscopic retrograde cholangiopancreatography: a retrospective expertisebased study from two centers. Therap Adv Gastroenterol 2017;10:483-93.

46. Moole H, Bechtold ML, Forcione D, et al. A meta-analysis and systematic review: Success of endoscopic ultrasound 
guided biliary stenting in patients with inoperable malignant biliary strictures and a failed ERCP. Medicine (Baltimore) 2017;96:e5154.

47. Siripun A, Sripongpun P, Ovartlarnporn B. Endoscopic ultrasound-guided biliary intervention in patients with surgically altered anatomy. World J Gastrointest Endosc 2015;7:283-9.

48. Khashab MA, El Zein MH, Sharzehi K, et al. EUSguided biliary drainage or enteroscopy-assisted ERCP in patients with surgical anatomy and biliary obstruction: an international comparative study. Endosc Int Open 2016;4:E1322-7.

49. Park JK, Woo YS, Noh DH, et al. Efficacy of EUS-guided doi: $10.21037 / \operatorname{tgh} .2018 .10 .10$

Cite this article as: Shah RM, Tarnasky P, Kedia P. A review of endoscopic ultrasound guided endoscopic retrograde cholangiopancreatography techniques in patients with surgically altered anatomy. Transl Gastroenterol Hepatol 2018;3:90. and ERCP-guided biliary drainage for malignant biliary obstruction: prospective randomized controlled study. Gastrointest Endosc 2018;88:277-282.

50. Dhir V, Itoi T, Khashab MA, et al. Multicenter comparative evaluation of endoscopic placement of expandable metal stents for malignant distal common bile duct obstruction by ERCP or EUS-guided approach. Gastrointest Endosc 2015;81:913-23.

51. Paik WH, Lee TH, Park DH, et al. EUS-Guided Biliary Drainage Versus ERCP for the Primary Palliation of Malignant Biliary Obstruction: A Multicenter Randomized Clinical Trial. Am J Gastroenterol 2018;113:987-97. 